This item was submitted to Loughborough's Research Repository by the author.

Items in Figshare are protected by copyright, with all rights reserved, unless otherwise indicated.

\title{
Maintenance cost implications of utilizing bathroom modules manufactured offsite
}

PLEASE CITE THE PUBLISHED VERSION

PUBLISHER

(c) Taylor \& Francis

VERSION

AM (Accepted Manuscript)

LICENCE

CC BY-NC-ND 4.0

\section{REPOSITORY RECORD}

Pan, Wei, Alistair G.F. Gibb, and Andrew B. Sellars. 2019. "Maintenance Cost Implications of Utilizing Bathroom Modules Manufactured Offsite". figshare. https://hdl.handle.net/2134/6184. 
This item was submitted to Loughborough's Institutional Repository (https://dspace.lboro.ac.uk/) by the author and is made available under the following Creative Commons Licence conditions.

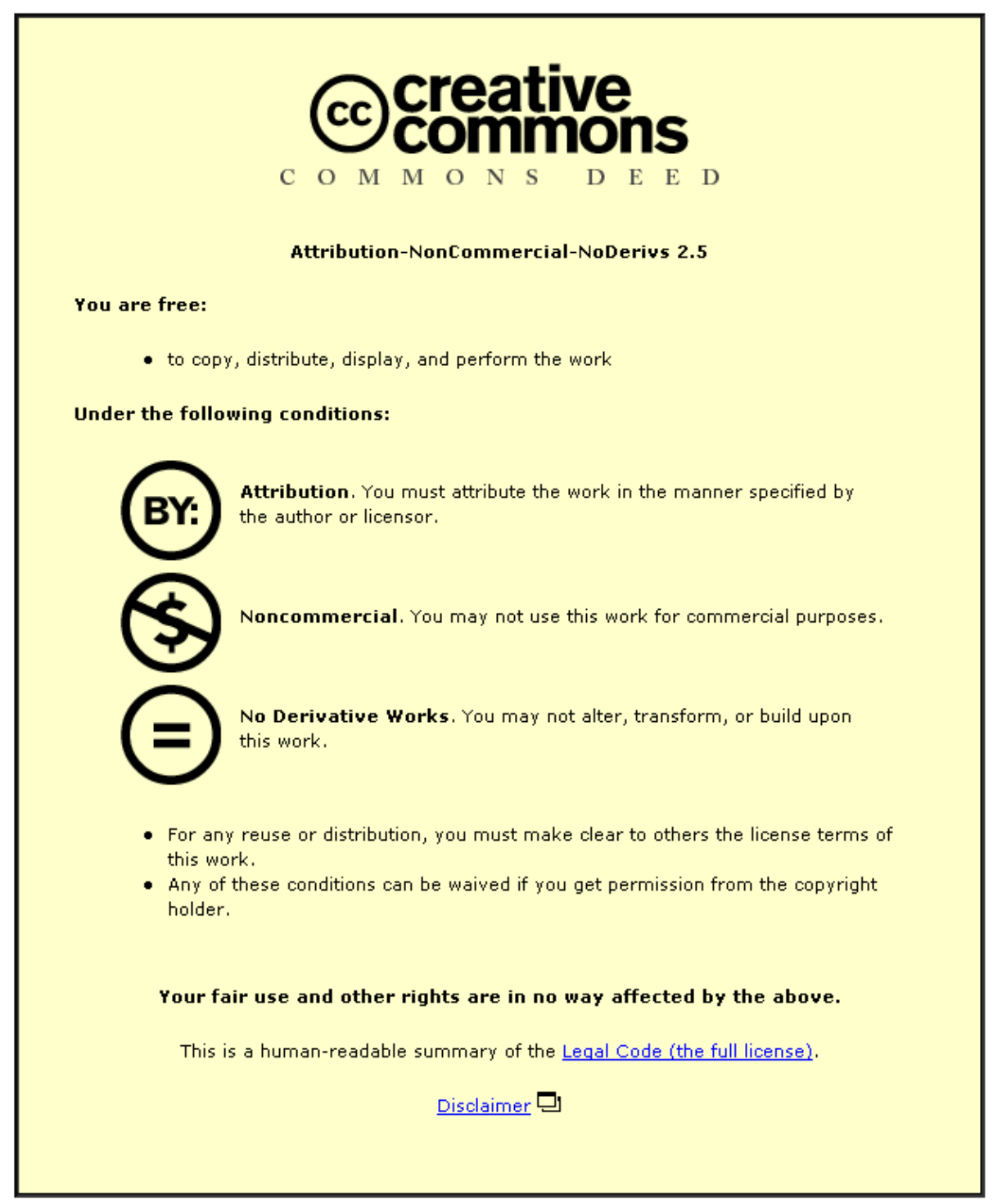

For the full text of this licence, please go to: http://creativecommons.org/licenses/by-nc-nd/2.5/ 


\title{
Maintenance cost implications of utilising bathroom modules manufactured offsite
}

\author{
WEI PAN ${ }^{1}$, ALISTAIR G. F. GIBB ${ }^{2}$ and ANDREW B. SELLARS ${ }^{2}$ \\ ${ }^{1}$ School of Engineering, University of Plymouth, Plymouth, UK \\ ${ }^{2}$ Department of Civil and Building Engineering, Loughborough University, \\ Loughborough, UK
}

\begin{abstract}
Though the benefits from using offsite technologies have been rehearsed, their uptake within the UK construction industry is slow. A critical barrier is the lack of cost data of using such technology. Another is the unsubstantiated perception that maintenance of offsite solutions is difficult and expensive. But, yet again, there appears to be no data publicly available on this topic. This knowledge gap is addressed by presenting the cost data of maintaining offsite and insitu bathrooms for student accommodation. The records of 732 maintenance jobs were investigated. These jobs span three years for 398 bathrooms, including precast concrete modules, Glass Reinforced Polyester (GRP) modules and insitu bathrooms. The results suggest that GRP modules required the lowest maintenance costs whilst insitu bathrooms were significantly more expensive to maintain. For offsite modules, drainage, toilets, vents and sink were identified as the main problematic areas for maintenance. The maintenance of insitu bathrooms was more complex and involved a wider range of problematic areas. The design imposed significant effects on the long-term cost of offsite bathrooms. Aspirations of clients need to be fully understood and integrated into design. The findings should facilitate the design decision-making of using offsite bathrooms for residential buildings.
\end{abstract}

Keywords: Bathroom modules, maintenance costs, offsite, student accommodation.

Please cite this paper as:

"Pan, W., Gibb, A.G.F. and Sellars, A.B. (2008) Maintenance cost implications of utilising bathroom modules manufactured offsite. Construction Management and Economics, 26(10), 1067-1077.”

*Author for correspondence. E-mail: wei.pan@plymouth.ac.uk 


\section{Introduction}

There has been an increasing interest in the use of offsite technology in the construction industry since the publication of the Egan Report (1998). The potential benefits from utilising such technology have been widely documented (see e.g. Gibb, 1999; Housing Forum, 2002; Pan et al., 2007). However, the current market value of offsite in the UK construction industry is around $£ 2.2$ billion, equivalent to $2.1 \%$ of the total construction turnover only (Goodier and Gibb, 2005). Such a level of usage of offsite in the UK seems to be lower than it could be. The lack of cost data of using offsite has been revealed as one of the most critical inhibiting factors to the increased use of offsite in the industry (see e.g. Gibb and Isack, 2003; Venables et al., 2004; Pan et al., 2007).

Building maintenance accounts for over $5 \%$ of the UK's gross domestic product, equivalent to over $£ 30$ billion a year, which makes it one of the largest industries in the UK economy (Wordsworth, 2001). However, the importance of maintenance has been largely underestimated as that has been regarded to be unproductive and as a 'Cinderella' activity (Seeley, 1987). The fact has been overlooked that buildings would deteriorate rapidly without proper maintenance. As one of the key areas of a building, bathrooms were identified to be critical to maintenance due to their significant maintenance risks and the likely association with a high number of defects (see Ramly et al., 2006). Though wet areas are usually not more than $10 \%$ of the building gross floor area, the annual maintenance cost for such areas can range from $35 \%$ to $50 \%$ of the total maintenance cost of a building (Chew and De Silva, 2003). This causes significant long-term costs for clients and great dissatisfaction for 
occupants. The emphasis on whole-life costing for offsite is becoming more of an issue in the choice of procurement route (Gardiner and Theobald, 2005).

Despite all these facts, the maintenance cost of utilising bathrooms manufactured offsite remains unclear. This is crucial as a lack of understanding of such cost will affect the design decision-making of what types of bathrooms to use and how to realise the full benefits of offsite technology. Our aim is to contribute to addressing this concern by investigating the costs of maintaining offsite bathroom modules for student accommodation. This investigation has been carried out in comparison with the maintenance of traditionally-built insitu bathrooms.

\section{Offsite bathroom modules}

Offsite bathroom modules are manufactured to create a volume of usable space, often called 'pods', built and tested within factory conditions (Gibb, 1999). Neale et al. (1993) described prefabricated bathroom modules as ready to use building elements as they come fully fitted with all fixtures and fittings and are commissioned ready for use. Given an increasing interest in improving bathroom conditions (Bathroom Manufacturers Association (BMA), 2006), bathroom manufacturers abound in the industry, and examples trading in the UK include Saniflex, Ensuite Solutions, R B Farquhar, E J Badekabiner, Gateway Fabrications, Module Modules, Fusion Build, and Concargo Composites. Though most manufacturers use different production methods, bathroom modules are generally available in timber frame, light steel frame, hot rolled steel frame, concrete or GRP structure, with suspended timber floor deck and plasterboard ceiling, and walls are generally plasterboard lined (National Centre for Excellence in Housing, 2006). 
Previous statistics suggested that the money spent on offsite bathroom/toilet modules/pods was around $£ 25$ million in 1989 (see Gibb, 1999). This, in itself, was relatively small, but it accounted for $30 \%$ of overall UK building services spend on offsite in that year with the total amount of $£ 84$ million (ibid). The use of bathroom and toilet pods is gathering momentum as offsite manufacture is being championed as the solution for the procurement of all large volume construction outputs in the established markets such as hotels, student accommodation and the MoD (Ministry of Defence) and health sectors of the UK industry (Davis Langdon and Everest, 2004; Gardiner and Theobald, 2005). Also, a survey of large new-build commercial office projects (more than $100,000 \mathrm{ft}^{2}$ ) reported that $20-30 \%$ of such schemes are using prefabricated toilet modules (see Gardiner and Theobald, 2005).

\section{Bathroom maintenance}

Seeley (1987) defined maintenance as the combination of all technical and associated administrative actions intended to 'retain' an item in, or 'restore' it to a state in which it can perform its required function. Son and Yuen (1993) explained that the term 'retain' means the defects that are prevented from developing by carrying out work in anticipation of failure, whilst the term 'restore' means that minor defects are allowed to occur before they are corrected. This explanation highlights the two main types of maintenance, reactive maintenance, which is to 'restore', and planned maintenance, which is to 'retain' (Spedding, 1994). Reactive maintenance focuses on reported defects and problems by the end user to the maintenance team. This is the same as repairs maintenance which is done as a reaction to requirement (Higgins et al., 1995). Planned maintenance is also called predictive or preventative which is 
carried out in plan even if there is nothing wrong with the property (Spedding, 1994). Levitt (2003) claimed that over $70 \%$ of all organisations he studied either do not use predictive maintenance or do very little towards it as this type of maintenance absorbs funding on something that has not yet gone wrong and the return is not instant and is hard to distinguish. Instead, most organisations use reactive or repairs maintenance for their properties. The maintenance strategy used by the University in this case study was reactive. Within this context and the definitions provided by previous studies, maintenance costs have been defined as the direct labour and materials costs occurred for repairs. This does not include regular cleaning costs or maintenance management overheads.

Manufacturers claim anecdotally that the maintenance profile of offsite modules is no difference to traditionally-built bathrooms (see e.g. R B Farquhar, 2006). Maintenance and replacement are even claimed to be eased through the use of offsite, provided the units are appropriately designed (Sparksman et al., 1999; Gardiner and Theobald, 2005). However, there is a great scarcity of reliable maintenance cost data available in a meaningful way (Seeley, 1987; Armstrong and Saville, 2005) and a few anecdotal 'horror-stories' are left to form a barrier against the increased use of offsite. Though some studies investigated the cost of using bathroom/toilet pods for offices (e.g. Davis Langdon and Everest, 2002) and hotels (e.g. Waterman, 2006), the maintenance costs of bathrooms for student accommodation has been overlooked. Also, most previous studies appeared to investigate individual types of bathroom or toilet pods. Few, however, have presented comparative analysis between offsite and insitu bathrooms. The lack of comparative cost data inhibits proper interpretation of the benefits from using offsite 
bathrooms. Within this context, we aim to contribute to an improved understanding of utilising offsite technology by examining the actual labour and materials costs occurred from maintaining offsite and traditionally-built insitu bathrooms. The offsite bathrooms investigated include GRP and precast concrete modules.

\section{Method}

The research aim has been achieved by in-depth investigation of 732 maintenance job records for 396 bathrooms, including offsite modules and traditionally built insitu bathrooms (Table 1).

(Insert Table 1 here)

This was carried out using case study methods of four student accommodation Residences in the same University across three consecutive years after their defects period. These four residences were selected for this study for their comparability (Table 2).

(Insert Table 2 here)

The details of these residences are provided as follows.

- Residence A was built in 1992 with 216 en suite bathrooms. These bathrooms were initially designed to be built using traditional methods. However, due to the time constraints of the project this decision was changed to using offsite methods. The main contractor chose precast concrete-framed bathroom modules. These modules were fully completed in factory, with only the connections to building services to be made on site following the installation. The use of bathroom modules facilitated on-time completion of this project. 
- Residence B had no major alterations until mid 1990's when the University required a fast and effective way of bringing old halls up to a modern standard. GRP bathroom modules were chosen as they were regarded as a relatively costeffective method of updating each room and boasting a quick installation with little alteration to the existing building. These modules were also fully completed in factory, with only the connections to building services to be made on site. There were 84 bathroom modules in total installed in this residence.

- Residence $C$ and $D$ consists of two blocks each, each block with 24 rooms. Each room was traditionally fitted with an en-suite bathroom. These used a combination of concrete block walls and dry-lined partitions with sanitary ware, plumbing, fixtures, fittings, services and tiling all installed on site. These 96 bathrooms, in total, were combined as one case study of traditionally-built insitu bathrooms. This helped achieve a principal match with the number of bathrooms in the other two case studies, which increased the comparability of data analysis.

For the case studies, quantitative data were collected by investigating the maintenance records retained by the Estates Department of the University. A database using Microsoft Excel spreadsheets was created, in which specific job numbers of records were stored to ensure that the maintenance problems can be tracked back to their records and associated labour and materials costs. This ensured the accuracy of data analysis and provided reliable tracks to original data. All maintenance records were also assessed to determine the nature of the problems, by which the problems were categorised. The categorised problems and their associated labour and materials costs were analysed in a comparative way. 
Exploring the constants and variables of these three cases (see Table 2) enabled the achievement of a reasonable comparison between the maintenance costs of bathrooms on a similar basis. Each bathroom includes the same main internal elements, i.e. a shower, toilet and sink. The structures of all residences into which the bathrooms were integrated were built using traditional brick and block with precast floor planks. Though the bathrooms were installed by different contractors which may imply different workmanship profiles, they all complied with building regulations and were all accepted by the university. All the bathrooms are similar in terms of their size. The factor of floor area would be important for comparing build costs, but, for maintenance costs, it is considered less relevant. However, the contents of the bathrooms, i.e. products and materials used for constructing the bathrooms, are regarded as having more cost implications on their maintenance. This is analysed and discussed in the rest of the paper on a more detailed level. Another key variable considered in this study was the different dates of installation of the bathrooms. Against this all cost data were indexed up to the end of 2006 using Building Maintenance Information (BMI) Maintenance Cost Indices (Building Cost Information Services (BCIS), 2007). This included BMI All-in maintenance cost indices - General (updated 23 November 2006) for labour costs and BMI maintenance materials cost indices (updated 21 November 2006) for materials costs. The cost data were collected for the periods after the 12-month defects period from the time when the bathrooms were installed, which ensured that the data collected were of maintenance work carried out by the University. The data collected cover three consecutive years of each residence. Although an ideal model of analysing costs should cover the data to date, that would be impractical for this research to handle given the time and resources available. 
The bulk of data is quantitative in nature, but qualitative descriptions were also provided where available. This helps to neutralise bias of the use of any single method (Creswell, 2003), to minimise the degree of specificity of certain methods (Gillham, 2000) and to provide insight into different levels or units of analysis (Tashakkori and Teddlie, 1998). Several semi-structured personal interviews with maintenance officials in the University's Estates Department were carried out to verify the results. For analysis the criterion ' $\%$ of overall maintenance costs' was used for identifying the most significant problematic areas. For the quantitative data descriptive statistical analysis was used, including both univariate (with one variable) and bivariate (with two variables) analysis (see Bryman, 2004), from which meaningful results were drawn and their implications were interpreted.

\section{Analyses and results}

The cost data collected were analysed comparatively. The top three most significant problems of each type of bathrooms were also identified and investigated. For analysing the data and interpreting the results several performance measures have been developed:

- Annual overall maintenance costs per bathroom (£/bathroom),

- Annual maintenance labour costs per bathroom (£/bathroom),

- Annual maintenance materials costs per bathroom (£/bathroom), and,

- Annual maintenance costs per bathroom for the top three most significant problems (£/bathroom), e.g. toilets, vents and drainage. 


\section{Comparative cost analysis}

First of all, traditionally built insitu bathrooms were the most expensive to maintain, with the annual average cost of $£ 73.50$ per bathroom (Figure 1). This maintenance cost became much cheaper for precast concrete modules (£39.63), and even less for GRP modules (£26.75). Secondly, the maintenance costs of precast bathroom modules were the most stable across the three years studied, with $9 \%$ variances or less from their annual average costs. For GRP bathroom modules the variances increased to $20 \%$ or less. However, the maintenance costs of traditional insitu bathrooms were inconsistent and changed significantly across the three years, with variances up to $68 \%$ of their annual average. The costs in Year 2 were significantly higher than others. Thirdly, the maintenance of GRP modules was more labourintensive (82\% labour costs) than of insitu (61\% labour) and precast modules $(60 \%$ labour).

(Insert Figure 1 here)

In terms of labour costs, precast and GRP modules shared similar maintenance profiles, with no substantial fluctuations across the three years. However, insitu bathrooms required significantly higher maintenance labour costs for the second year (£70 per bathroom). The costs for the first and third year dropped substantially to around $£ 30$ per bathroom, but were still higher than the offsite modules. As for materials costs, GRP modules had the cheapest profile, with their annual material costs only £6.28 per bathroom or less. The materials cost profiles of precast modules for three years and insitu bathrooms for the first and third year were similar, within 
the range from $£ 15$ to $£ 18$ per bathroom. However, the materials cost of insitu bathrooms for the second year was significantly higher ( $£ 52.90$ per bathroom).

\section{Detailed analysis of concrete modules (Residence A)}

The top three most problematic areas for precast modules were identified as drainage, toilets and vents. These areas, collectively, contributed the vast majority (83\% and $80 \%$ respectively) to the overall maintenance costs for both Year 1 and 2 (Figure 2). Despite a slight decrease their contribution in Year 3 was still over two thirds (68\%). There was no significant difference between the maintenance cost contributions from the top three areas, all falling in the range from $21 \%$ to $32 \%$. Tile damages, though not noticeable at all in Year 1 and 2, generated considerable maintenance costs in Year $3(10 \%)$. There was also some money spent on maintaining shower heads/controller units and sink, but much less significant (both less than $8 \%$ ) than for the top areas.

(Insert Figure 2 here)

Breakdown analysis of labour and materials costs of the top three most significant problematic areas provides an insight into the maintenance profile of concrete bathroom modules. There seems to be a general alternative increase-and-decrease pattern of costs for maintaining these top areas (Figure 3).

(Insert Figure 3 here) 
The change trend of the costs also appears to show a general decrease from Year 1 to 3. Materials costs for maintaining vents and toilets were comparatively stable across the years, somewhat higher than their counterpart of labour costs. However, the maintenance costs for drainage were predominated by labour for all three years, which were also much higher than the labour costs for vents and toilets. This predominant labour costs for maintaining drainage was probably due to the design factor that the drainage pipes were cast into the modules. This caused difficulty to access the pipes for maintenance. This design issue was associated with the prototype of the concrete modules, but was not told to the client at the beginning of the project. The Estates Manager explained that the main contractor made the decision to use precast bathroom modules, not the client. The client's main concern at that time was the timing completion of the project as the residence had been booked for the start of the new term. In terms of maintaining the toilets, the costs of materials were moderately higher than that of labour across the three years. Though the overall costs were $£ 10.20$ and $£ 11.30$ per bathroom for Year 1 and 2 respectively, that dropped substantially in Year 3 (£7.60). This shows a less labour-intensive maintenance profile for toilets than for drainage. Most toilet problems were associated with toilet seats which were either lost or broken. These problems were not directly related to the design, but arose during the usage of the toilets. Also, the service risers were tightly packed with service pipes. The replacement of this pipe work required some of the surrounding pipes to be removed so that proper access to the required area can be provided. This might have had an impact on the problems with the toilets as the waste pipes of the toilets were directed down through the service risers. Problems with vents were largely associated with the extract fans in use. Comparing to drainage and toilets, vents were associated with the highest proportion of materials 
costs, which was incurred by replacing fan filters. In addition to these main areas, most sink problems were associated with blockage and leakage. That was mainly due to the small size of the waste pipes used in the modules. The waste pipes used for showers were also found to be undersized.

\section{Detailed analysis of GRP modules (Residence B)}

Drainage was identified as the most problematic area for this residence, which caused an extremely high percentage $(62 \%)$ of costs in Year 2 in particular (Figure 4). The estates officials explained that the waste pipes were too small, which caused these significant problems with drainage for GRP modules. Toilets appeared to be the second most problematic area in both Year $1(22 \%)$ and Year $2(19 \%)$. Toilet problems were largely due to the design factor that the cisterns were located behind the GRP façade above the toilets. This made it difficult to access the cisterns for repairs. The estates officials claimed that access to the cistern lid, arguably, can be provided by removing the flush push plate above the toilet. However, this could only provide a limited working space through the hole of the flush plate in which all repairing work had to be performed. Sink problems were the most significant in Year $1(24 \%)$. Though it dropped substantially in Year 2 to $5 \%$, it increased to $11 \%$ in Year 3. The sink problems were mainly associated with the taps used. Typical examples included leakage, loose control and the inability to spin round. Serious problems also existed in leakage in Year $3(24 \%)$ and lighting in Year $1(18 \%)$.

(Insert Figure 4 here) 
Drainage, toilets and sinks were regarded as the top three most significant problematic areas in GRP modules. The breakdown analysis of labour and materials costs of these top areas suggests a general alternative increase-and-decrease pattern of maintenance costs. However, the overall costs for drainage across the three years fluctuated more significantly than for toilets and sinks (Figure 5). For all three areas the maintenance costs were predominated by labour costs. The labour cost for maintaining drainage in Year $2(£ 17.41 /$ bathroom) was significantly higher than others (£7.43 in Year 3 or much less for other areas). This predominant labour cost for maintaining drainage was probably due to the design factor that the drainage pipes were cast into the modules. This caused difficulty to access the pipes for maintenance. The problems with toilets were mainly due to the fact that most cisterns were hidden and difficult to access, which made the repairs highly labour-intensive and expensive.

(Insert Figure 5 here)

\section{Detailed analysis of insitu bathrooms (Residence $C \& D$ )}

The maintenance costs for shower heads/controller units, leakage and tile damage were significantly higher than for others (Figure 6). The maintenance costs for all of the areas changed to some extent through the three years. However, the costs of repairing tile damages were extremely variable, being very modest in Year 1 (3\% of all) but with a radical increase in Year 2 to 37\%. Though it dropped down to $16 \%$ in Year 3, it was still more significant than most of the other areas.

(Insert Figure 6 here) 
The labour and materials cost breakdown analysis of these areas also suggests a general alternative increase-and-decrease pattern of the costs for insitu bathrooms (Figure 7). The repair of tile damages and leakages was more labour-intensive than of shower heads/controller units. This suggests that the problems with shower heads/controller units were relatively simpler and easier to solve as long as the materials were available. In terms of repairing leakages, the labour costs in Year 1 (£13.20/bathroom) were substantially higher than the material costs (£2.70). However, the labour costs (£12.70) dropped in Year 2 whilst the materials costs increased significantly (£9.00). This suggests that there might be a significant amount of investigation carried out in Year 1 to identify the leaking problems, whilst many of that were not repaired until Year 2. This suggestion also helps explain the fact that both labour and materials costs dropped dramatically in Year 3.

(Insert Figure 7 here)

\section{Discussion}

Empirical evidence about utilising offsite technology has been generated. It has quantified the cost implications of maintaining offsite and traditional insitu bathrooms for student accommodation. The findings of both the comparative study and breakdown analysis of individual types of bathrooms are discussed within the context of existing knowledge.

The results of the analysis show that the maintenance costs of offsite modules can be almost as low as one third of insitu bathrooms. This finding not only confirms, but 
also quantifies, the argument by previous study (see e.g. Gardiner and Theobald, 2005) that modules built in factory conditions should lead to inherently better quality with fewer defects and therefore lower lifecycle costing. This finding is important to help clients and their professional advisors achieve a reasonable lifecycle cost comparison between offsite and insitu bathrooms. Most of the issues where problems were encountered had been exacerbated by poor design decisions which were not related to the method of manufacture. Quality is fundamentally a design issue. Products that have been designed well are more likely to be built well if they are manufactured in factory conditions. However, poorly-designed products do not 'magically' become good just by manufacturing them offsite.

Gardiner and Theobald (2005) claimed that the production of volumetric toilet pods will normally add about $10 \%$ to the cost of traditional on-site production though the rate can be dependent on the quality of material and finish specified and volume repetition. Some argue that the cost premium of specifying factory-fitted bathroom pods can even rise up to $30 \%$ compared with traditional bathroom fit-outs (see Waterman, 2006). To counter this view, research at Loughborough University (Blismas et al., 2006) has established that the main reason that the first costs of offsite solutions are often considered to be more expensive is that the comparison is not sensitive enough to the real outturn costs encountered on real projects. The decision support tool IMMPREST (www.IMMPREST.com) has been developed to provide a means for fair and accurate comparison of real value between offsite and on-site options (Blismas et al., 2005). Nevertheless, understanding maintenance costs properly is critical as the cost of operating and maintaining a building can be 
appropriately five times the cost of capital over the life of the building (Royal Academy of Engineering, 1999).

The breakdown analysis of labour and materials costs suggests that the maintenance of insitu bathrooms was more reliant on new materials to keep them in working order. Precast modules also required a considerable amount of materials for maintenance, but less often. However, maintaining GRP modules imposed modest requirement for new materials. Though these results are based on data across only three consecutive years, they suggest a possibility that some materials and/or products used for the insitu bathrooms were not within expected quality standards. They required maintenance/change on a more frequent basis than for the units manufactured in controlled factory conditions.

The analysis suggests a general increase-decrease-increase alternative pattern of the trend of the maintenance costs. This was mainly attributed to the reactive maintenance strategy used by the University rather than pre-planned or preventative. Therefore, due to the comparatively higher number of repairs reacted in Year 2 the number of problems reduced substantially in Year 3. The significant high labour costs for insitu bathrooms in the second year was not surprising as this type of bathroom required the highest materials costs, and therefore would probably impose the highest labour requirement to fit the amount of materials required. Another reason for the trend of labour and materials costs was that the services of GRP modules were more difficult to access. This poor accessibility to the fittings took the maintenance team longer time than normal to perform a relatively simple task, which caused significant increases of labour costs. This finding emphasises the importance 
of providing access for maintenance for all bathrooms, whether offsite or insitu. Module designers should ensure access to services for maintenance. Ross et al. (2006) suggested that the accessibility should be provided either within the module or in the adjacent construction.

\section{Strategies for reducing bathroom maintenance costs}

The discussion of our findings within the context of existing knowledge suggests several strategies that could be used to reduce bathroom maintenance costs. First of all, the concept of maintenance needs to be integrated into the design strategy for prefabricated bathroom modules at early project stages. This approach should take into account reliability, durability, maintainability and whole life costing (El-Haram and Horner, 2002). The results of this research show that the drainage and toilets problems with offsite bathrooms were largely associated with the design of the modules. They could have been addressed at the design stage, which could then have dramatically reduced their associated maintenance costs. However, designs of modules available in the market can vary substantially from each other, which can make access and repair difficult and problematic. Because of this, the client may wish to review the design of production technologies from a low-cost and easy maintenance point of view. This commitment would be important for them to realise the benefits of using offsite technology (see e.g. Gibb and Isack, 2003). Also, the improved design should ensure the selection of good quality component materials/products, which, in return, will help reduce the lifecycle maintenance costs.

Secondly, the "lean thinking" approach (see Kempton, 2006) could be applied for improving efficiency of repairs. However, as Kempton suggested, leaning thinking 
may be much more difficult to apply to the reactive type of repairs. The University in this study adopted reactive maintenance strategy, which determined that the maintenance work was not organised in a planned way, but on an ad hoc basis.

Thirdly, as the maintenance profiles of all three types of bathrooms were all labourintensive, it is critical to reduce the labour work in order to reduce maintenance costs. This supports the strategy provided by El-Haram and Horner (2002: 117) for reducing housing maintenance costs, i.e. "reducing the duration of maintenance tasks by increasing the accessibility, planning maintenance resources in advance and training of maintenance staff'. Finally, reducing the impact of influencing factors to maintenance other than those discussed above should also help reduce the maintenance costs of offsite bathrooms. These factors may include occupants' usage and workmanship of build and repair (see e.g. Idris, 1998; El-Haram and Horner, 2002; Waterman, 2006). The data of maintenance cost implications of these factors are not available and, therefore, not included in this study. However, general knowledge suggests that good workmanship of build and repair and proper usage by occupants should help improve lifecycle performance of bathrooms.

There is a limited amount of usable information on bathroom maintenance despite considerable recent research into offsite applications in general. For this reason the discussion of our results within a wider context is constrained. But the resultant quantified maintenance costs of utilising offsite and insitu bathrooms and related strategies for reducing such costs enable the conclusion of this paper, from which future research is also recommended. 


\section{Conclusions and future research}

We have investigated the maintenance costs of precast concrete modules, GRP modules and traditional insitu bathrooms in a comparative manner. The research suggests that GRP modules require the lowest maintenance costs, followed by concrete modules, but traditionally-built insitu bathrooms being associated with the highest costs. The results emphasise the importance of integrating the concept of maintenance into early design stages. The approach of designing for low-cost and easy maintenance needs to be embraced in order to address clients' aspiration of reducing lifecycle costs. This research has provided empirical evidence of utilising offsite technology, and also pushed forward the boundary of knowledge by quantifying the cost implications of maintaining offsite and insitu bathrooms. This research provides a worked example of measuring maintenance cost performance of offsite in a quantitative manner. This is important as it contributes quantitative evidence to demonstrating the benefits from using offsite, which will likely encourage the uptake of such technology in the industry. The quantitative maintenance cost data should help clients and their professional advisors with selecting appropriate types of bathrooms for their projects. Clients' aspirations should be fully understood and integrated into design in order to achieve an effective use of offsite technology.

The maintenance cost data were based on student accommodation buildings. Care should be taken for interpreting the results within other built environment sectors. Any quantitative generalisation, or called 'sampling logic' (see Bryman, 2004), of the findings needs to be reviewed, but 'the replication logic' (see Yin, 2003) should remain valid. Also, caveats should be made for generalising the findings to the 
context in which different maintenance strategies are adopted. Further study could be carried out to compare the costs of maintaining bathrooms in different types of buildings, e.g. hotels, offices and housing. This would increase the knowledge of bathroom maintenance costs in broader areas and reduce any potential bias of views on particular building types. Study combining maintenance costs and capital costs would help supply chains understand better the overall performance of offsite technology, which would enable more robust, transparent lifecycle cost comparison of different types of bathrooms.

\section{References}

Armstrong, J. and Saville, A. (2005) Managing your building services, The Chartered Institute of Building Services Engineers (CIBSE) Knowledge Series, 30pp. ISBN 1903287553.

Bathroom Manufacturers Association (BMA) (2006) 2006 Market Trends, BMA, Stoke on Trent.

Blismas, N.G., Gibb, A.G.F. \& Pasquire, C.L. (2005) Assessing project suitability for offsite production. The Australian Journal of Construction Economics \& Building, Australian Institute of Quantity Surveyors, 5(1), 9-15.

Blismas, N.G., Gibb, A.G.F. \& Pasquire, C.L. (2006) Benefit evaluation for offsite production in construction. Construction Management and Economics, 24(2), 121-30.

Bryman, A. (2004) Social Research Methods, 2nd Edn. Oxford University Press, Oxford.

Building Cost Information Services (BCIS) (2006) Building Maintenance Information (BMI) Maintenance Cost Indices, updated November 2006, BCIS on-line services.

Chew, M.Y.L. and De Silva, N. (2003) Maintainability problems of wet areas in high-rise residential buildings. Building Research and Information, 31(1), 60-9. 
Creswell, J.W. (2003) Research Design: Qualitative, Quantitative, and Mixed

Methods Approaches, 2nd Edn. Sage Publications, Thousand Oaks,

California.

Davis Langdon and Everest (2002) Prefabrication and Preassembly - Cost model.

Building, 15 February (6), 67-72.

Davis Langdon and Everest (2004) Off-site manufacturer - Cost model. Building, October (42), 67-72.

Egan, J. (1998) Rethinking Construction: The Report of the Construction Task Force,

Department of the Environments, Transport and the Regions, London.

El-Haram, M.A. and Horner, M.W. (2002) Factors affecting housing maintenance cost. Journal of Quality in Maintenance Engineering, 8(2), 115-23.

Gardiner \& Theobald (2005) Spotlight on toilet pods. Building, 25 November (47).

Gibb, A.G.F. (1999) Off-site Fabrication: Prefabrication, Pre-assembly and Modularisation. Whittles Publishing, Caithness.

Gibb, A. G. F. and Isack, F. (2003) Re-engineering through pre-assembly: client expectations and drivers. Building Research \& Information, 31(2), 146-60.

Gillham, B. (2000) Case Study Research Methods, Continuum, London.

Goodier, C. and Gibb, A. (2005) The value of the UK market for offsite, Buildoffsite, London. Available at www.buildoffsite.co.uk (20/12/2005).

Higgins, L.R., Brautigam, D.P. and Mobley, R.K. (1995) Maintenance Engineering Handbook, (eds), $5^{\text {th }}$ Edn. McGraw-Hill, New York.

Housing Forum (2002) Homing in on excellence: A commentary on the use of off-site fabrication methods for the UK housebuilding industry, The Housing Forum, London.

Idris, M.M. (1998) Assessment of the factors influencing the maintenance programme of a large university building in Riyadh. Construction Management and Economics, 16(6), 673-9.

Kempton, J. (2006) Can lean thinking apply to the repair and refurbishment of properties in the registered social landlord sector. Structural Survey, 24(3), 201-11.

Levitt, J. (2003) Complete Guide to Preventative and Predictive Maintenance, Industrial Press Inc., New York.

National Centre for Excellence in Housing (2006), http://www.homein.org/page.jsp?id=643, accessed 28/03/2007. 
Neale, R., Price, A. and Sher, W. (1993) Prefabricated Modules in Construction: A study of the current practice in the United Kingdom, The Chartered Institute of Building (CIOB), Ascot.

Pan, W., Gibb, A.G.F. and Dainty, A.R.J. (2007) Perspectives of UK housebuilders on the use of offsite modern methods of construction. Construction Management and Economics, 25(2), 183-94.

R B Farquhar (2006) www.rbfarquhar.co.uk/faqs/faqs.asp\#, accessed 02/01/06.

Ramly, A., Ahmad, N.A. and Ishak, N.H. (2006) The effects of design on the maintenance of public housing buildings in Malaysia - Part two. Building Engineer, May, 34-6.

Ross, K., Cartwright, P. and Novakovic, O. (2006) A guide to modern methods of construction, HIS BRE Press on behalf of NHBC Foundation, Amersham, Bucks.

Royal Academy of Engineering with Evans, R., Haryott, R., Haste, N. and Jones, A. (1999) The long term costs of owning and using buildings, The Royal Academy of Engineering, London.

Seeley, I.H. (1987) Building Maintenance, MacMillan Press Ltd, Basingstoke, UK. Son, L.H. and Yuen, G.C.S. (1993) Building Maintenance Technology, MacMillan Press Ltd, London.

Sparksman, G., Groak, S., Gibb, A. and Neale, R. (1999) Standardisation and Preassembly: Adding Value to Construction Projects, Construction Industry Research and Information Association (CIRIA), London.

Spedding, A. (1994) CIOB Handbook of Facilities Management, Longman Group Ltd, London.

Tashakkori, A. and Teddlie, C. (1998) Mixed methodology: Combining qualitative and quantitative approaches, Sage, Thousand Oaks, CA.

Venables, T., Barlow, J. and Gann, D. (2004) Manufacturing Excellence: UK Capacity in Offsite Manufacturing, The Housing Forum, London.

Waterman, A. (2006) Costs: Bathroom fit-outs. Building, 14 February (6).

Wordsworth, P. (2001) Lee's Building Maintenance Management. $4^{\text {th }}$ Edn. Blackwell Science, London.

Yin, R. K. (2003) Case Study Research: Design and Methods, 3rd Edn. Sage, Thousand Oaks, California. 
Figures are in the sequence referred to in the paper.

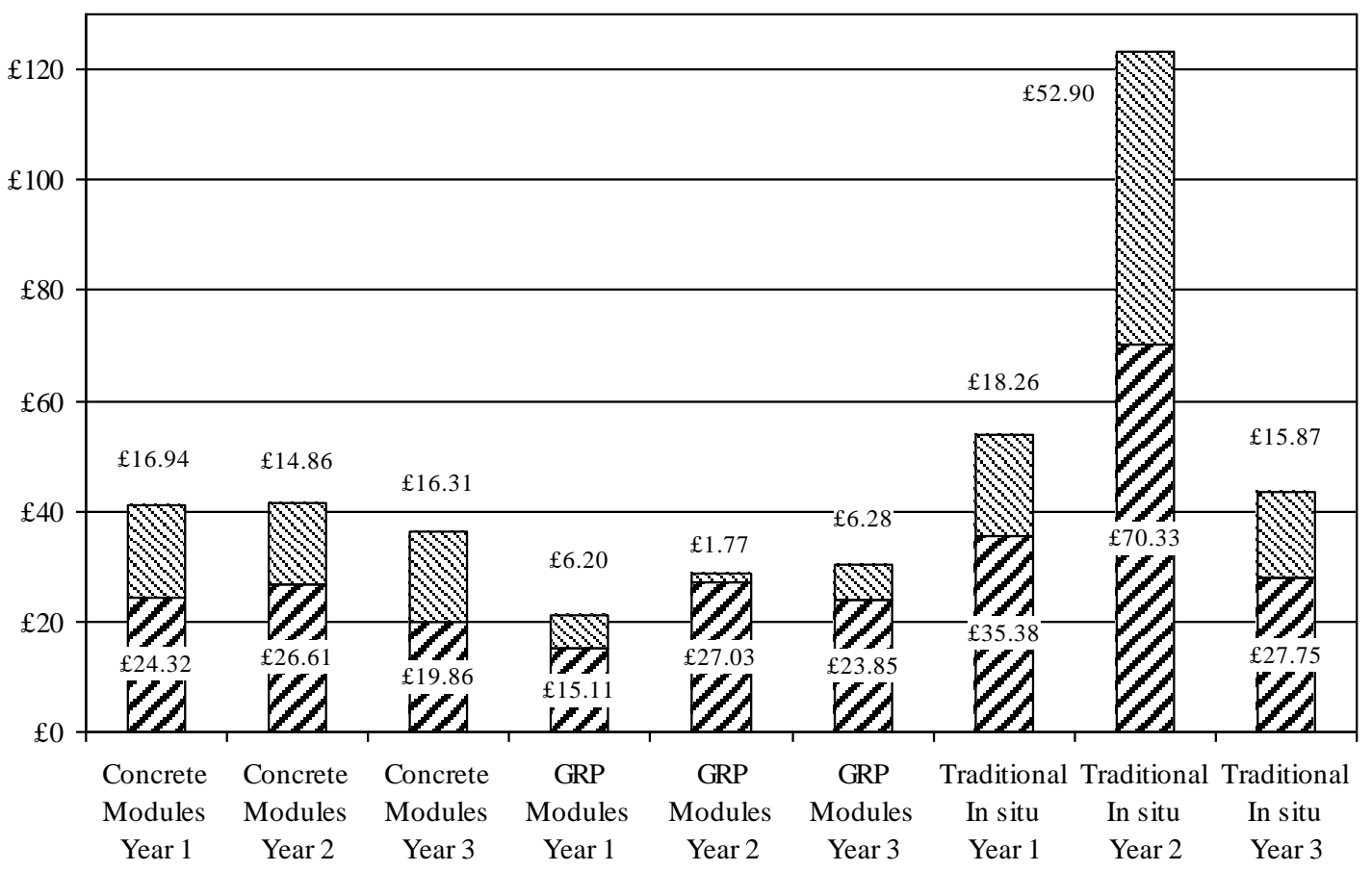

Figure 1 Maintenance cost profile of three types of bathrooms
$\square$ Labour cost per bathroom
Materials cost per bathroom

Notes: All costs have been indexed to December 2006 using BMI maintenance cost indices (BCIS, 2006). 


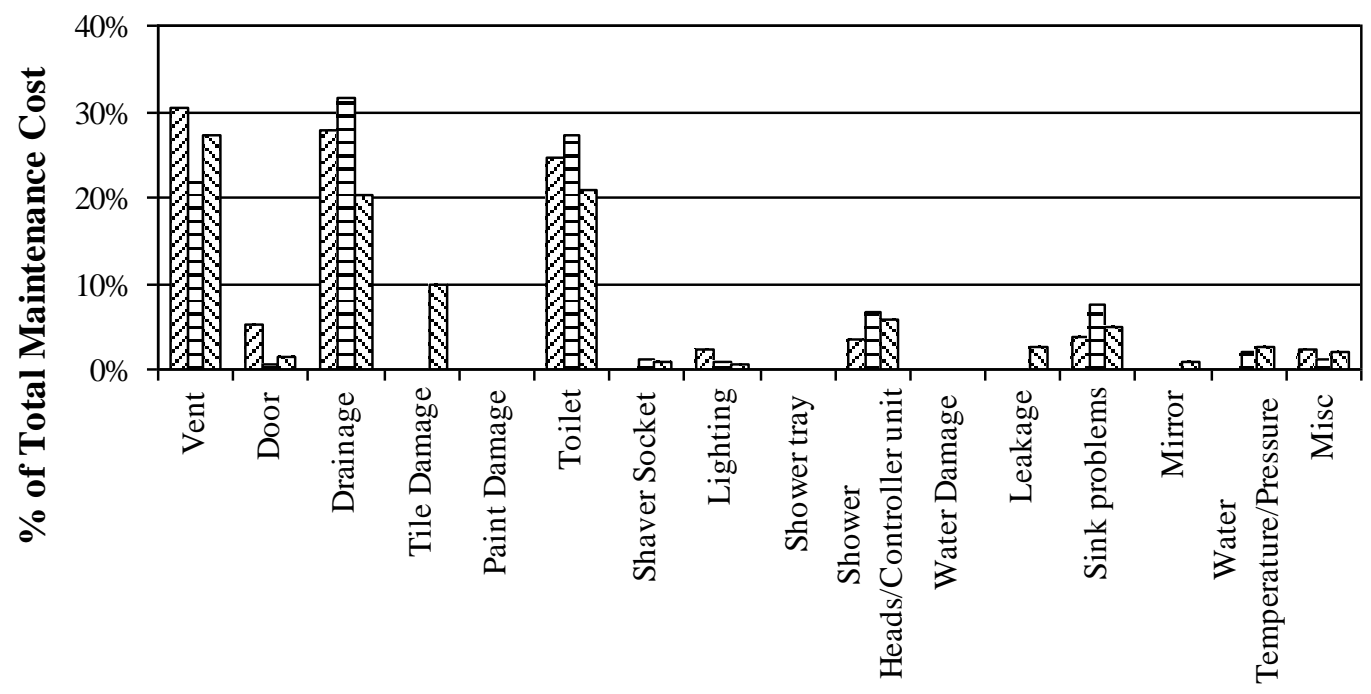

Figure 2 Problematic areas (\% of overall maintenance costs) of concrete modules
\Year 1
目 Year 2
$\mathbb{\$}$ Year 3 


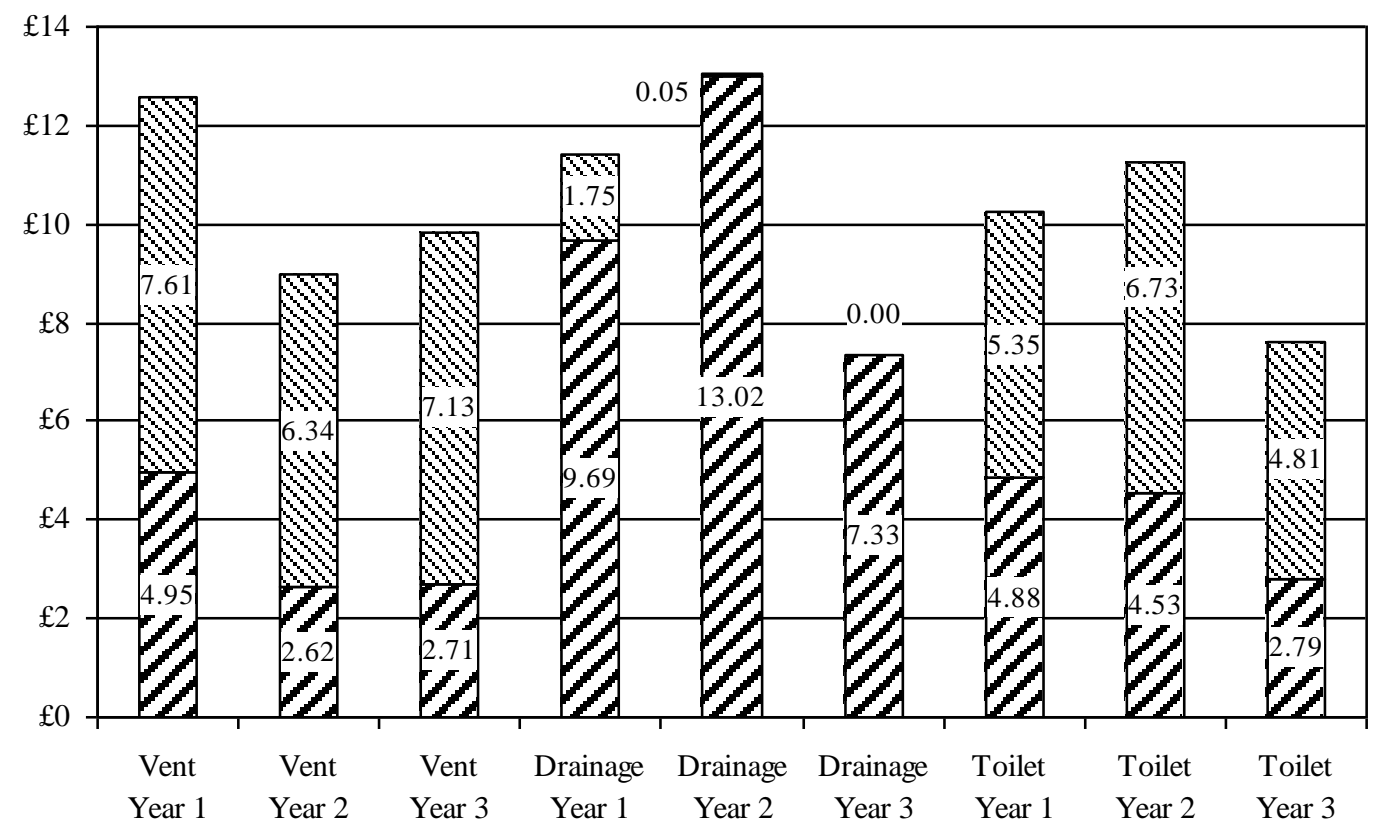

Figure 3 Maintenance costs of the top three most problematic areas of concrete modules

$\square$ Labour cost per bathroom

@ Materials cost per bathroom 


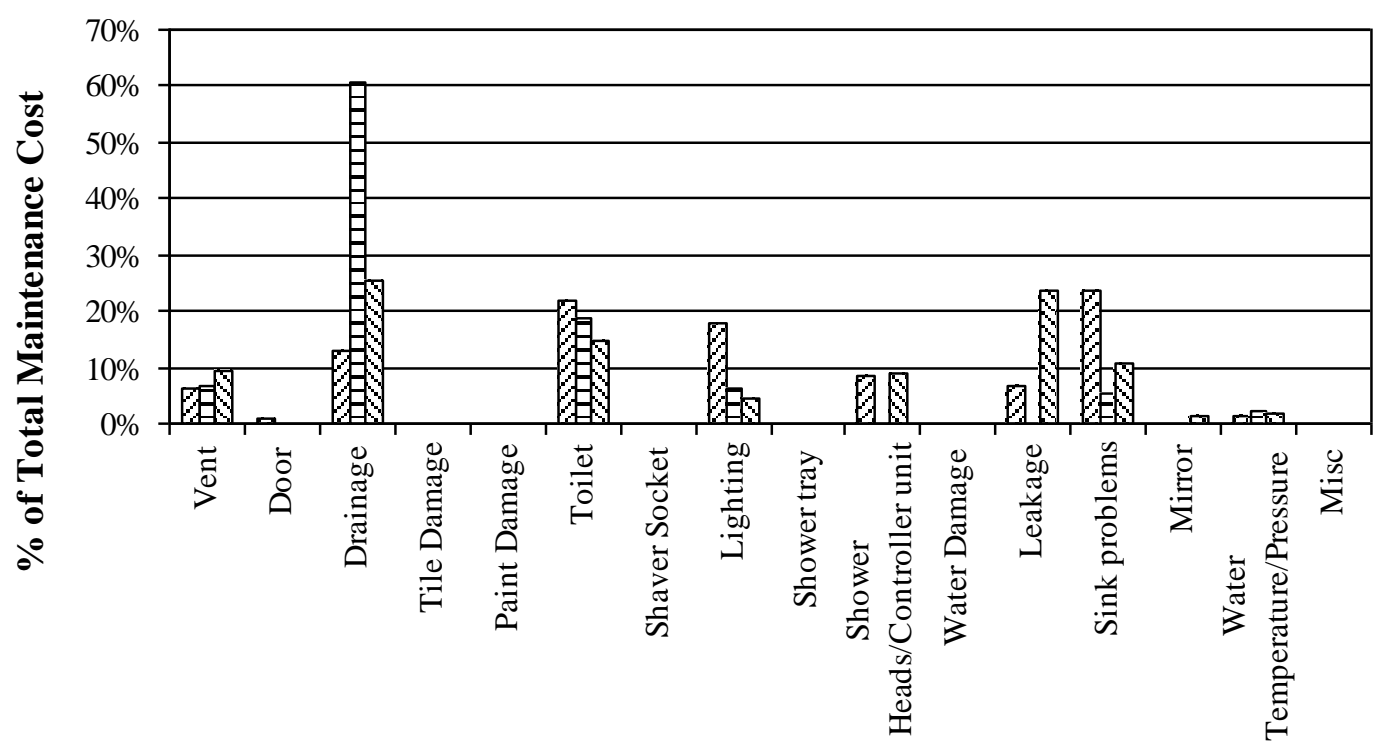

Figure 4 Problematic areas (\% of overall maintenance costs) of GRP modules
\ Year 1
日 Year 2
\$ Year 3 


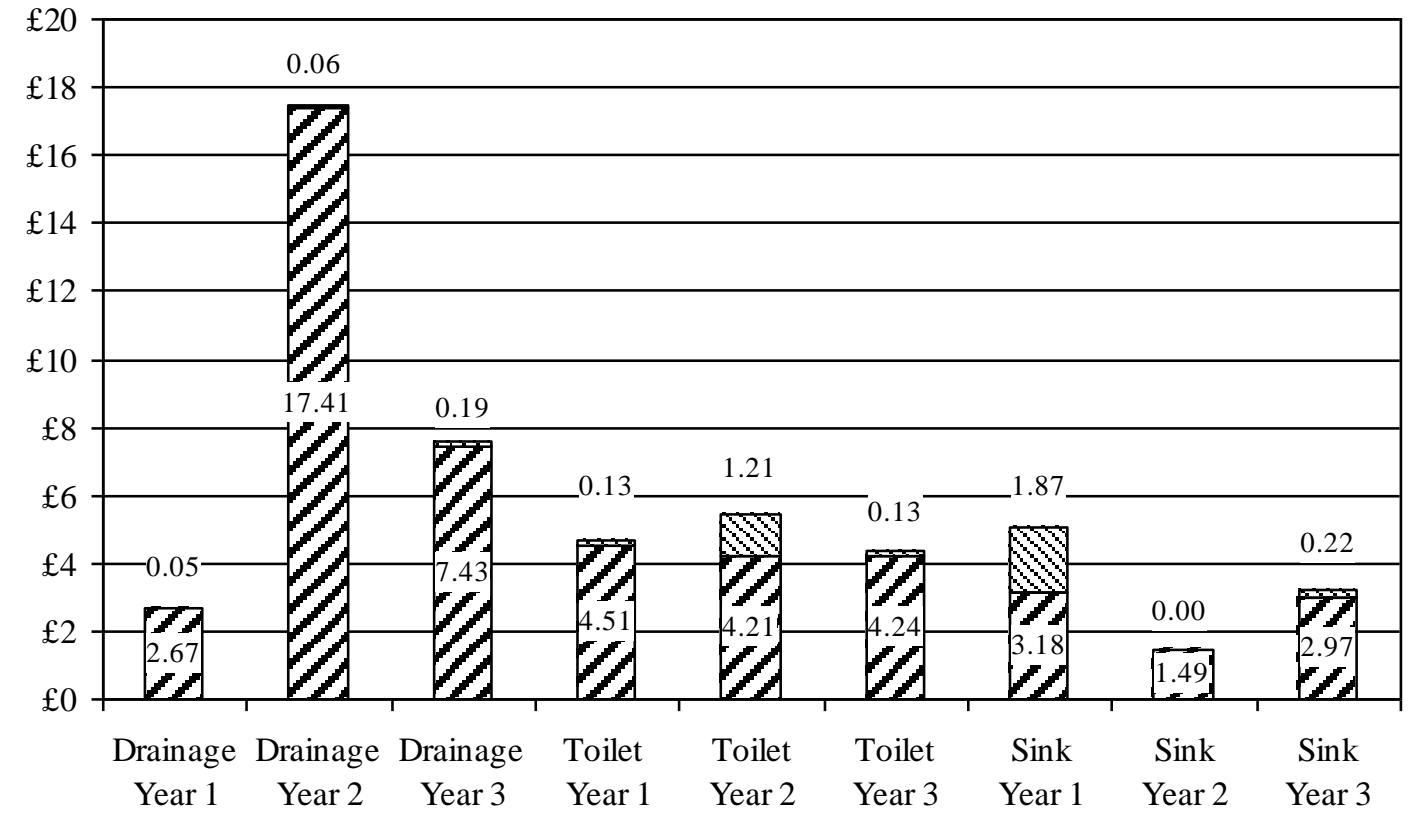

Figure 5 Maintenance costs for the top three most problematic areas of GRP modules
$\square$ Labour cost per bathroom
\$ Materials cost per bathroom 


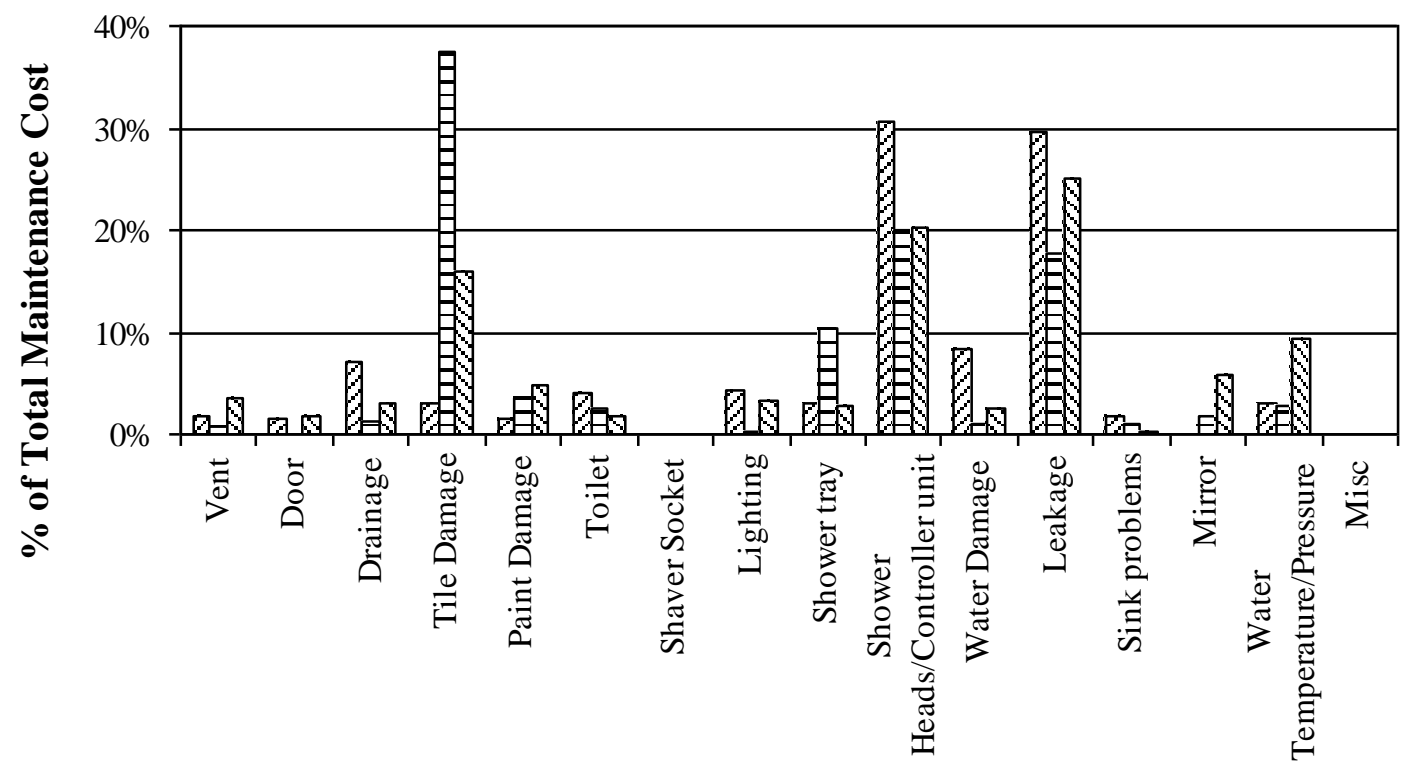

Figure 6 Problematic areas (\% of overall maintenance costs) of insitu bathrooms
Year 1
目 Year 2
$\mathbb{\$} \quad$ Year 3 


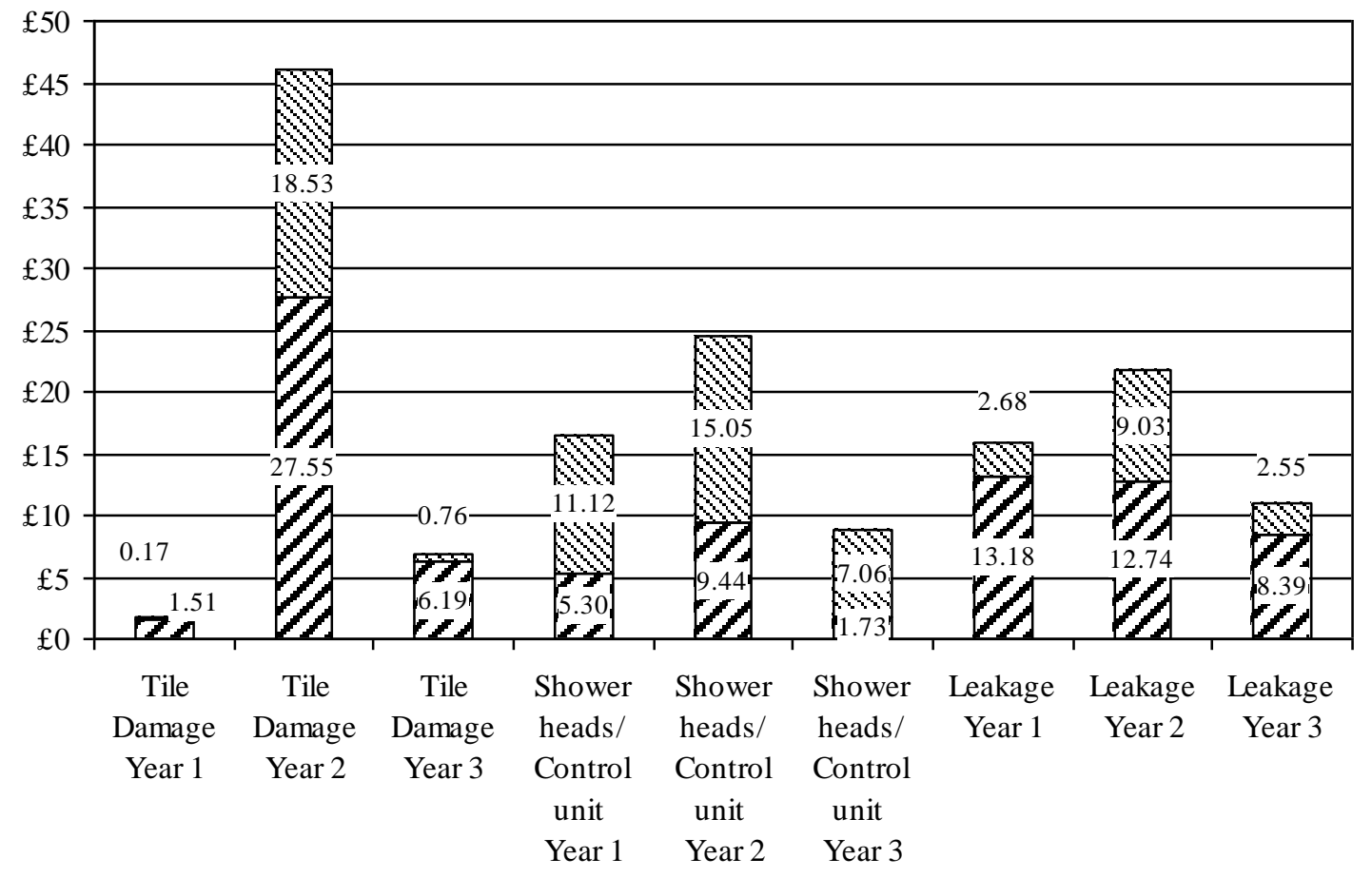

Figure 7 Maintenance costs for the top three most problematic areas of insitu bathrooms

Labour cost per bathroom

$\mathbb{N}$ Materials cost per bathroom 
Tables are in the sequence referred to in the paper.

\begin{tabular}{clcc}
\hline Residence & Type of bathrooms & No. of bathrooms & No. of problems recorded \\
\hline A & Concrete modules & 216 & 409 \\
B & GRP modules & 84 & 120 \\
C & Traditionally-built insitu & 48 & 85 \\
D & Traditionally-built insitu & 48 & 118 \\
Total & & $\mathbf{3 9 6}$ & $\mathbf{7 3 2}$ \\
\hline
\end{tabular}

Table 1 Case study sample of bathrooms and maintenance problems

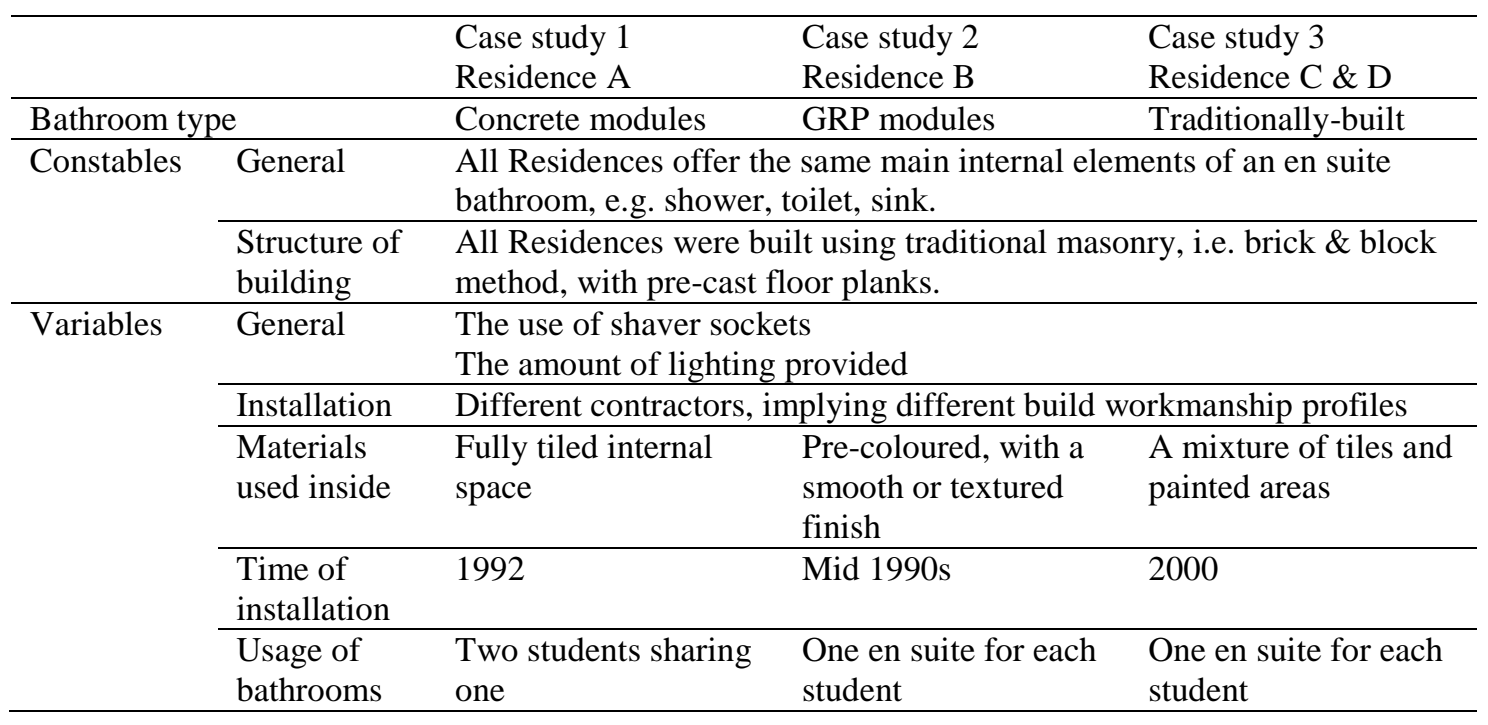

Table 2 Constables and variables of comparative case studies 